Article

\title{
Low Infection of Phelipanche aegyptiaca in Micro-Tom Mutants Deficient in CAROTENOID CLEAVAGE DIOXYGENASE 8
}

\author{
Shoko Hasegawa ${ }^{1}$, Takuya Tsutsumi ${ }^{2}$, Shunsuke Fukushima ${ }^{2}$, Yoshihiro Okabe ${ }^{3,4}$, \\ Junna Saito ${ }^{5}$, Mina Katayama ${ }^{6}$, Masato Shindo ${ }^{1}$, Yusuke Yamada ${ }^{1}$, Koichiro Shimomura ${ }^{1}$, \\ Kaori Yoneyama ${ }^{7,8}$, Kohki Akiyama ${ }^{5}$, Koh Aoki ${ }^{5}$, Tohru Ariizumi ${ }^{3,4}$, Hiroshi Ezura ${ }^{3,4}$, \\ Shinjiro Yamaguchi ${ }^{9}$ and Mikihisa Umehara ${ }^{1,2, *(\mathbb{D})}$
}

1 Graduate School of Life Sciences, Toyo University, Itakura-machi, Ora-gun, Gunma 374-0193, Japan; stm4022xqi@gmail.com (S.H.); shindo.masato.03@gmail.com (M.S.); dwarf1012y.y@gmail.com (Y.Y.); shimomur@toyo.jp (K.S.)

2 Department of Applied Biosciences, Toyo University, Itakura-machi, Ora-gun, Gunma 374-0193, Japan; gq01queen@gmail.com (T.T.); fksm.ss0807@gmail.com (S.F.)

3 Faculty of Life and Environmental Sciences, University of Tsukuba, Tsukuba, Ibaraki 305-8572, Japan; yoshihiro.okabe13@gmail.com (Y.O.); ariizumi.toru.ge@u.tsukuba.ac.jp (T.A.); ezura.hiroshi.fa@u.tsukuba.ac.jp (H.E.)

4 Tsukuba Plant Innovation Research Center, University of Tsukuba, Tsukuba, Ibaraki 305-8572, Japan

5 Graduate School of Life and Environmental Sciences, Osaka Prefecture University, Naka-ku, Sakai, Osaka 599-8531, Japan; syc02042@edu.osakafu-u.ac.jp (J.S.); akiyama@biochem.osakafu-u.ac.jp (K.Ak.); kaoki@plant.osakafu-u.ac.jp (K.Ao.)

6 College of Life, Environment, and Advanced Sciences, Osaka Prefecture University, Naka-ku, Sakai, Osaka 599-8531, Japan; ymy.mk.ymy@gmail.com

7 Graduate School of Agriculture, Ehime University, Matsuyama, Ehime 790-8566, Japan; yoneyama.kaori.wx@ehime-u.ac.jp

8 Precursory Research for Embryonic Science and Technology (PRESTO), Japan Science and Technology Agency, Kawaguchi, Saitama 332-0012, Japan

9 Graduate School of Life Sciences, Tohoku University, Katahira, Aoba-ku, Sendai 980-8577, Japan; shinjiro@m.tohoku.ac.jp

* Correspondence: umehara@toyo.jp; Tel.: +81-276-82-9144

Received: 8 August 2018; Accepted: 4 September 2018; Published: 6 September 2018

\begin{abstract}
Strigolactones (SLs), a group of plant hormones, induce germination of root-parasitic plants and inhibit shoot branching in many plants. Shoot branching is an important trait that affects the number and quality of flowers and fruits. Root-parasitic plants, such as Phelipanche spp., infect tomato roots and cause economic damage in Europe and North Africa-hence why resistant tomato cultivars are needed. In this study, we found carotenoid cleavage dioxygenase 8-defective mutants of Micro-Tom tomato (slccd8) by the "targeting induced local lesions in genomes" (TILLING) method. The mutants showed excess branching, which was suppressed by exogenously applied SL. Grafting shoot scions of the slccd8 mutants onto wild-type (WT) rootstocks restored normal branching in the scions. The levels of endogenous orobanchol and solanacol in WT were enough detectable, whereas that in the slccd8 mutants were below the detection limit of quantification analysis. Accordingly, root exudates of the slccd8 mutants hardly stimulated seed germination of root parasitic plants. In addition, SL deficiency did not critically affect the fruit traits of Micro-Tom. Using a rhizotron system, we also found that Phelipanche aegyptiaca infection was lower in the slccd8 mutants than in wild-type Micro-Tom because of the low germination. We propose that the slccd8 mutants might be useful as new tomato lines resistant to $P$. aegyptiaca.
\end{abstract}


Keywords: carotenoid cleavage dioxygenase 8; Orobanche minor; Phelipanche aegyptiaca; shoot branching; Solanum lycopersicum; strigolactones

\section{Introduction}

Shoot branching determines aerial plant architecture, which is controlled by the formation of axillary buds in the axils of leaves and subsequent outgrowth [1]. Shoot branching is an important trait in agriculture and horticulture because it affects the flower numbers, as well as number and quality of fruits and seeds. Therefore, it is important to control number of branches in crop production. Whether axillary buds start to grow or remain dormant is governed by environmental and endogenous cues [2]. The main endogenous cues are plant hormones; cytokinin activate axillary bud outgrowth, whereas auxin, which is transported basipetally, inhibits it [3]. Strigolactones (SLs) also inhibit axillary bud outgrowth $[4,5]$. Several types of natural SLs have been found in root exudates of diverse plant species [6].

SLs are synthesized from $\beta$-carotene in plastids. $\beta$-Carotene is first converted to carlactone (CL) through consecutive reactions catalyzed by the $\beta$-carotene isomerase and carotenoid cleavage dioxygenases 7 and 8 (CCD7 and CCD8) $[7,8]$. In rice and pea, CCD8 expression is regulated by negative feedback through SLs $[9,10]$. In Arabidopsis, CL is converted to a non-canonical SL, carlactonoic acid, via oxidation by CYP711A1, a cytochrome P450 encoded by MORE AXILLARY GROWTH1 (MAX1) [11]. In rice, CYP711A2 catalyzes the oxidation of CL into a canonical SL, 4-deoxyorobanchol (4-DO), and CYP711A3 catalyzes the hydroxylation of 4-DO to produce the strigolactone orobanchol [12].

SL production is induced in roots under inorganic phosphate (Pi) deficiency in several plant species, including tomato, red clover, sorghum, Lotus japonicus, alfalfa, and rice [4,13-16]. In wild-type (WT) rice, shoot branching is not inhibited under Pi-sufficient conditions, because SL levels are low in roots [17]. Under Pi deficiency, SL levels in roots are highly elevated and SLs are probably transported to axillary buds, where they inhibit bud outgrowth [17]. Furthermore, SLs are released into soil where they likely stimulate symbiotic interactions with arbuscular mycorrhizal fungi, which supply Pi to the host plants [18]. In SL mutants of rice and Arabidopsis, shoot branching is not suppressed under Pi deficiency $[17,19]$. Therefore, SLs are thought to be key regulators of efficient Pi allocation and adaptation to Pi deficiency [20]. Recently, SL production is shown to be induced in response to nitrogen and sulfate deficiencies, as well as Pi deficiency in rice [21,22].

Tomato (Solanum lycopersicum L.), a major horticultural crop in the Solanaceae, is a model system for fruit development with a sequenced genome [23]. Tomato produces several orobanchol-type SLs, including orobanchol, solanacol, didehydro-orobanchol, orobanchyl acetate, 7-oxoorobanchol, and 7-hydroxyorobanchol [24]. Knock-down tomato lines of CCD7 and CCD8 have been generated by antisense introgression and RNAi-mediated silencing, respectively [25,26]. Recently, the max 1 mutant with defective CYP711 of tomato has been characterized [27]. In these low-SL lines, plant height is reduced, and the number of branches is increased. In addition, flower size, seed number, and fruit yield are reduced in SlCCD8 knock-down lines, indicating that SLs contribute to crop yield [25].

SLs were originally characterized as germination inducers in root-parasitic plants [28,29]. SLs are released from roots into soil and induce germination of Striga, Orobanche, and Phelipanche species [30,31]. Phelipanche ramosa and Phelipanche aegyptiaca parasitize the roots of important crops, including tomato, and cause severe economic damage in some areas around the Mediterranean [32]. Therefore, new tomato cultivars resistant to root-parasitic plants are needed in these areas.

Previously, we demonstrated that few Striga hermonthica plants infected roots of the $C C D 8$-defective rice mutant $d 10$ [4]. In this study, to evaluate the infection of SL biosynthesis-defective mutants with P. aegyptiaca, we found two CCD8-defective mutant lines, 2757 and 5291, in Micro-Tom tomato by using the "targeting-induced local lesions in genomes" (TILLING) method (Okabe et al. 2011). We characterized that both mutants had more shoot branches than WT and no detectable 
endogenous SLs. Exogenously applied GR24 (a synthetic SL analog used for evaluation of physiological effects of SLs; [33]) and grafting onto WT rootstock suppressed the excess outgrowth of axillary buds in the mutants. Few seeds of P. aegyptiaca and Orobanche minor germinated in root exudates of the mutants. Furthermore, P. aegyptiaca infection was lower in 5291 roots than in WT roots because of the low germination of P. aegyptiaca.

\section{Results}

\subsection{Screening for SlCCD8-Defective Micro-Tom Mutants}

Among ca. 9000 mutant Micro-Tom lines stocked in the University of Tsukuba within the framework of National Bio-Resource Project Tomato (Saito et al. 2011), we found 12 candidates for slccd8 mutants (Table S1) including lines 8245 and 7311 having the same point mutation in the SICCD8 gene. The $\mathrm{M}_{3}$ plants of the 12 candidates were grown, and each mutation in each line was checked by cleaved amplified polymorphic sequence (CAPS) analysis or DNA sequencing of the SlCCD8 gene. However, we could not find homozygous mutants in lines 7343, 7024, 7311, 5639, 7720, 2481, 5550, and 3979. Such homozygous were found in lines 8245 and 8940, but the number of branches, orobanchol levels, and germination of $O$. minor did not differ from those of WT (Table S1). In the recessive homozygous mutants of 5291 and 2757, the number of branches was higher than that in WT, orobanchol was not detected in root exudates, and the root exudates did not stimulate seed germination of $O$. minor (Table S1). The mutation in 5291 was identified as a change of $C$ to $T$ at +2578 th nucleotide from the transcriptional start, resulting in a change of 494th amino acid serine to phenylalanine (Table S1). The mutation in 2757 was identified as a change of G to A at +2616 th nucleotide, resulting in a change of 507th glutamic acid to lysine (Table S1). In both mutants, these mutations were located in the fifth exon of SICCD8 (Figure S1A). Homozygous mutants of 5291 and 2757 were propagated, checked by CAPS analysis with specific primers (Table S2, Figure S1B), and used for following experiments. When the amino acid sequences of CCD8 were compared in some plant species, 494th serine and 507th glutamic acid were conserved (Figure S2).

\subsection{SL Levels Are Reduced in the slccd8 Mutants 5291 and 2757}

To investigate in which tissues of WT Micro-Tom SlCCD8 is strongly expressed, we performed quantitative real-time PCR (qRT-PCR) analysis using specific primers and TaqMan probes listed in Supplementary Table S2. We grew WT seedlings in the phosphate ion presence $(+\mathrm{Pi})$ or absence ( $-\mathrm{Pi}$ ) of hydroponic culture medium and assayed SICCD8 mRNA expression in stems, roots, leaves, and shoot apices of 20-day-old seedlings (Figure 1A). SICCD8 expression was very low under $+\mathrm{Pi}$ conditions, but was elevated in stems, shoot apices, and especially in roots under - Pi conditions (Figure 1B). It was much lower in fruits than in other tissues, but slightly increased in orange fruits.
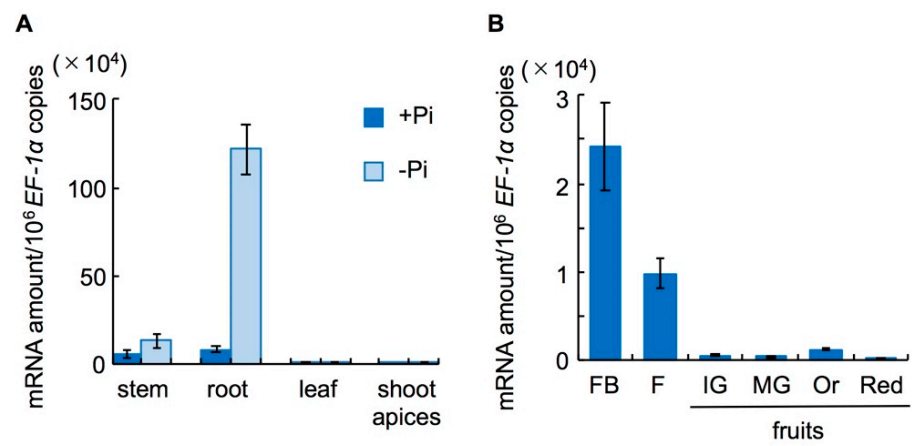

Figure 1. Quantitative real-time PCR (qRT-PCR) analysis of SlCCD8 expression in wild-type (WT) Micro-Tom tomato. (A) Twenty-day-old seedlings. (B) Mature 120-day-old plants. FB, flower bud; F, flower; IG, immature green fruits; MG, mature green fruits; Or, orange fruits; Red, red fruits. Error bars, Standard error (S.E.) $(n=4)$. 
Next, we quantified endogenous SLs in roots using liquid chromatography-tandem mass spectrometry (LC-MS/MS). Under -Pi conditions, orobanchol concentration in WT was $20.6 \mathrm{pg} \cdot \mathrm{L}^{-1}$ in root exudates and $272.2 \mathrm{pg} \cdot \mathrm{g}^{-1} \mathrm{FW}$ in roots (Figure $2 \mathrm{~A}, \mathrm{~B}$ ); solanacol concentration was $12.8 \mathrm{pg} \cdot \mathrm{L}^{-1}$ in root exudates and $74.7 \mathrm{pg} \cdot \mathrm{g}^{-1} \mathrm{FW}$ in roots (Figure 2C,D). In lines 5291 and 2757, these SLs were undetectable in root exudates and roots (Figure 2A-D). In germination assays, root exudates of WT seedlings induced germination of $43.4 \%$ of O. minor seeds and $59.5 \%$ of P. aegyptiaca seeds (Figure 2E,F). Root exudates of 5291 and 2757 did not stimulate germination of O. minor seeds (Figure 2E) and induced germination of approximately $1 \%$ of P. aegyptiaca seeds (Figure $2 \mathrm{~F}$ ).
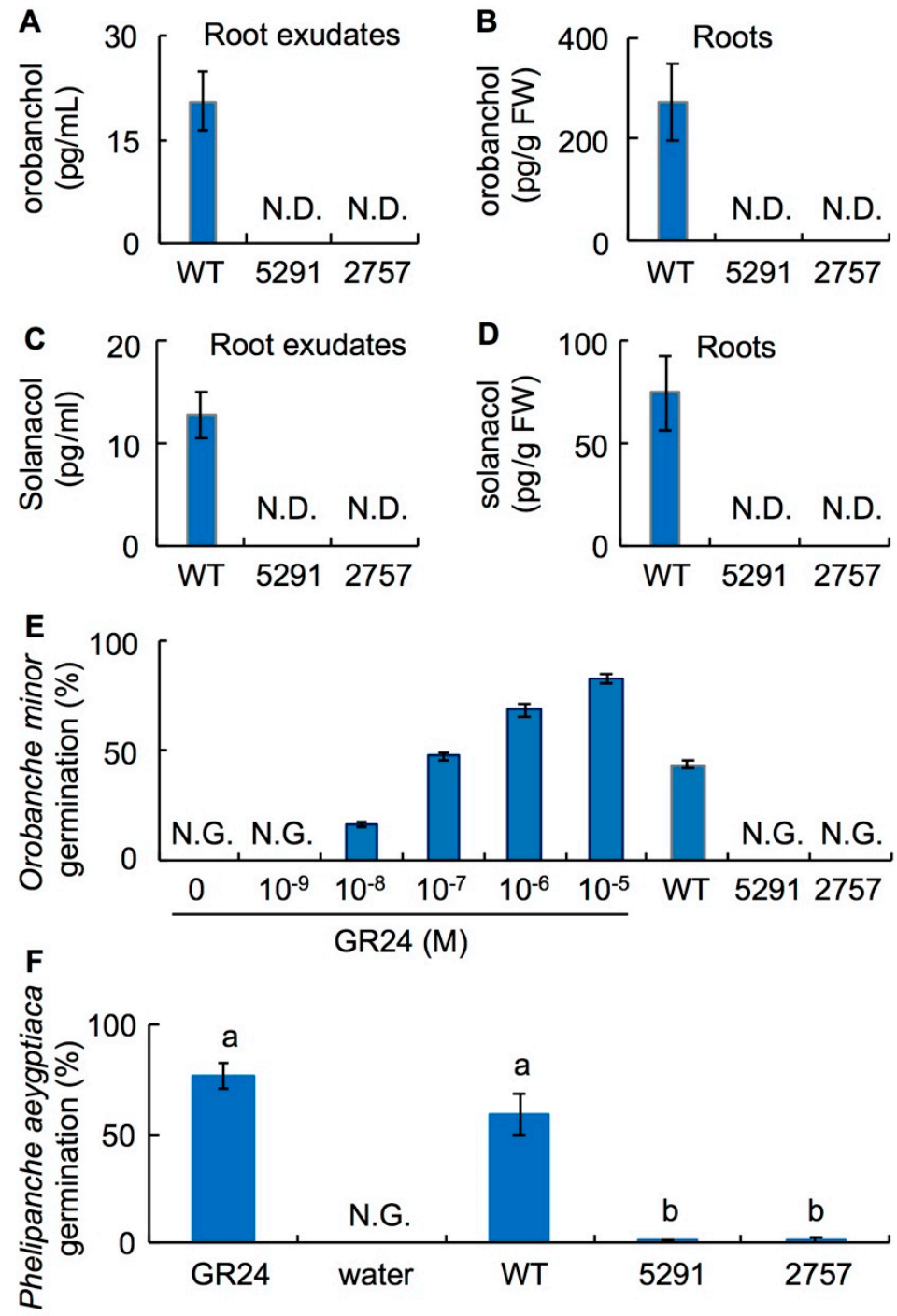

Figure 2. Orobanchol and solanacol levels in root exudates and roots of WT and lines 5291 and 2757, and germination assays with root-parasitic plants. (A) $n=6$. (B) $n=5$. (C) $n=10$. (D) $n=5$. (E,F) Germination assays using $(\mathbf{E})$ Orobanche minor $(n=6)$ or $(\mathbf{F})$ Phelipanche aegyptiaca. Error bars, S.E.; N.D., not detected; N.G., no germination.

\subsection{Characterization of the Slccd8 Mutants 5291 and 2757}

Among 30-day-old seedlings, WT had 1-4 axillary buds longer than $2 \mathrm{~mm}$, whereas 5291 and 2757 had 4-7 (Figure 3). Exogenously applied GR24 $(1 \mu \mathrm{M})$ suppressed axillary bud outgrowth of 5291 and 2757 to the WT levels (Figure 4, Figure S3). To evaluate the effect of endogenous SLs, we performed grafting experiments (Figure 5, Figure S4). To eliminate the effect of grafting, WT was grafted onto WT and slccd8 mutant was grafted onto slccd8 mutant. Grafting of WT shoot scions onto WT or 
slccd8 mutant rootstocks resulted in similar numbers of branches. Grafting of slccd8 mutant shoot scions onto WT rootstocks decreased the number of branches in comparison with that on slccd8 mutant rootstocks. Under - Pi conditions, orobanchol and solanacol were produced in WT rootstocks, but were undetectable in slccd8 mutant rootstocks (Figure 6, Figure S5).

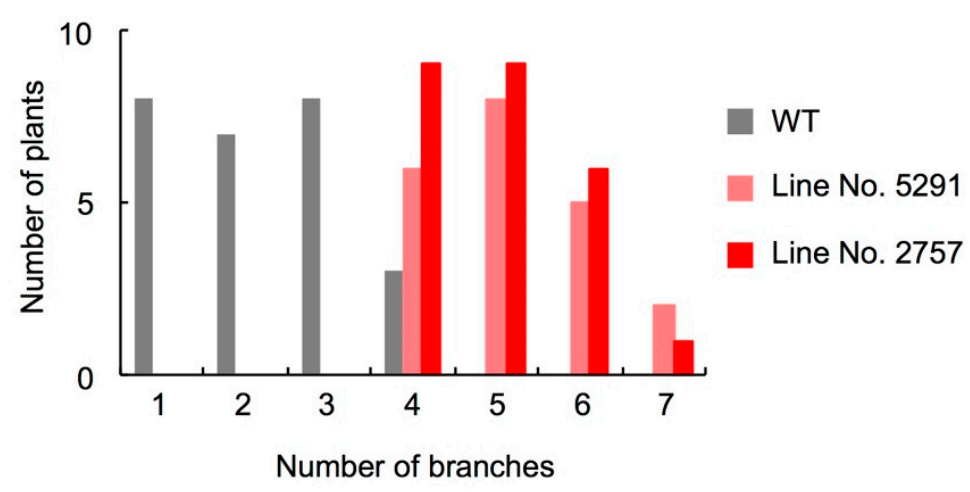

Figure 3. Number of branches in WT and SlCCD8-defective mutants. Axillary buds longer than $2 \mathrm{~mm}$ were counted in 30-day-old seedlings. WT, $n=26$; line 5291, $n=29$; line 2757, $n=25$.

A

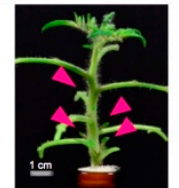

WT (-GR24)

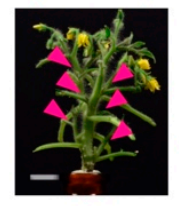

5291

(-GR24)

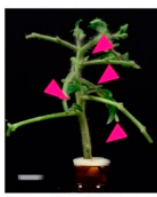

WT (+GR24)

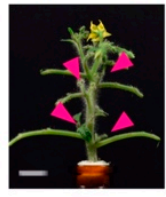

5291

(+GR24)

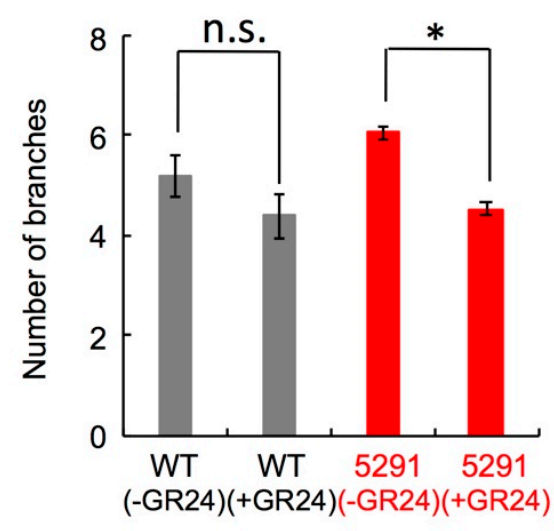

B

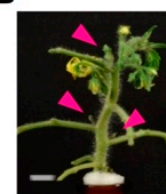

WT (-GR24)

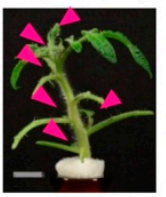

2757

(-GR24)

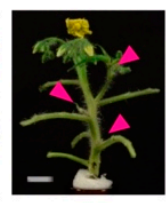

WT
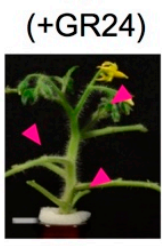

2757

(+GR24)

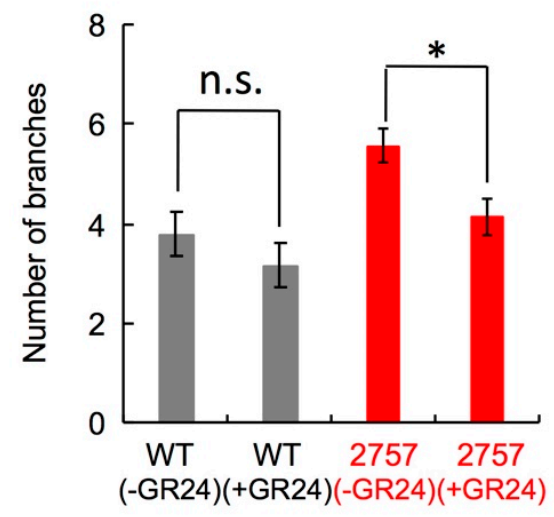

Figure 4. Effect of exogenously applied strigolactone (SL) on branching. GR24 $(1 \mu \mathrm{M})$ was applied to 40-day-old seedlings of WT and (A) line $5291(n=3)$ or $(\mathbf{B})$ line $2757(n=4)$. Arrowheads show outgrowing axillary buds ( $>2 \mathrm{~mm}$ ). Error bars, S.E. Student's $t$-test, ${ }^{*} p<0.05$, Asterisks indicate significant differences between untreated and treated slccd8 mutants (Student's $t$-test, ${ }^{*} p<0.05$; n.s., not significant). 
In rice and Arabidopsis, CCD8-defective mutants have delayed leaf senescence [34,35], but no delay in leaf senescence was observed in 5291 (Figure S6). Among a number of flower and fruit traits examined (Figure S7), the number of branches increased in slccd8 mutants (Figure 3), but the number of flowers and fruits did not increase in 2757 and it decreased in 5291; interestingly, Brix slightly (but significantly) increased in both slccd8 mutants.
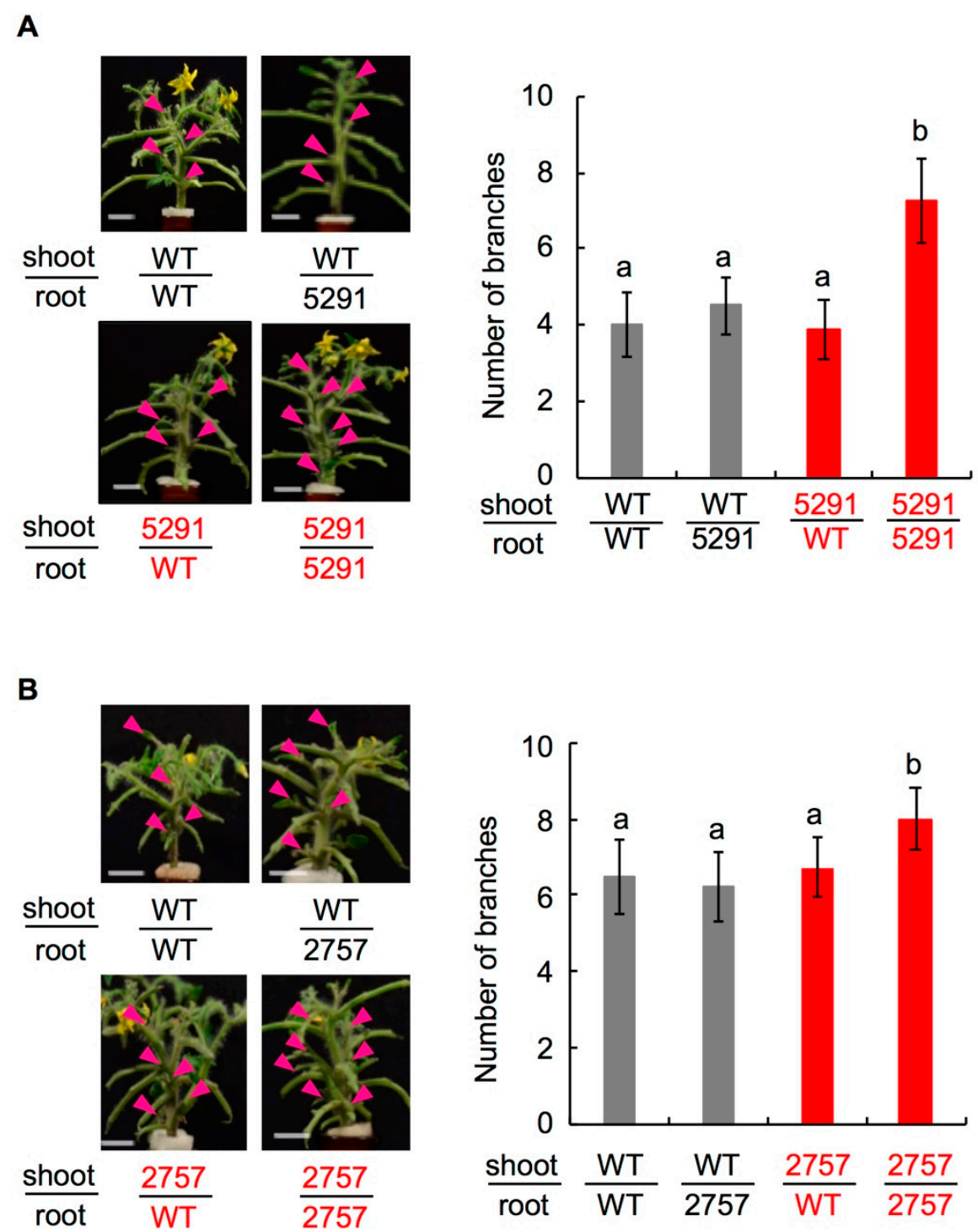

Figure 5. Effect of endogenous SL on branching. Photographs show 60-day-old plants grafted using scions and rootstocks from WT, and (A) line 5291 or (B) line 2757 as indicated. Arrowheads show outgrowing axillary buds. Branches were counted for 50 days. Error bars, S.D. Different lowercase letters show significant difference by Tukey's multiple comparison test $(p<0.05)$.

\subsection{Phelipanche aegyptiaca Infection Is Decreased in Roots of Slccd8 Mutants}

To evaluate the impact of low SL levels on the interaction of Micro-Tom with root-parasitic plants, we performed an infection assay with P. aegyptiaca. Germination of P. aegyptiaca seeds was approximately $55 \%$ at 10 days after inoculation (DAI) and $57 \%$ at 20 DAI around WT roots, but was significantly lower (21\% at $10 \mathrm{DAI}$ and $23 \%$ at $20 \mathrm{DAI}$ ) around 5291 roots (Figure $7 \mathrm{~A}$ ). Some germinated P. aegyptiaca infected tomato roots at $20 \mathrm{DAI}$. The proportions of spherical and protrusion tubercles were $2.5 \%$ and $14.7 \%$ in WT, respectively, and $1.0 \%$ and $7.4 \%$ in 5291 (Figure 7A). There was no significant 
difference in the proportion of tubercle formation in P. aegyptiaca after germination between WT and 5291 (Figure 7B).

\section{Discussion}

CCD8 converts 9-cis- $\beta$-apo-10'-carotenal to carlactone in plastids [7]. This reaction is an important step to form the basic chemical structure of SLs in SL biosynthesis. The role of the CCD8 gene has been characterized in several plant species [25,36-38]. Using the TILLING method, we found two slccd8 mutants (5291 and 2757) of Micro-Tom tomato and characterized their growth traits. In both mutants, point mutations are located in the fifth exon, which is important for catalysis (Supplementary Figure S1). In WT seedlings, the highest expression of the SlCCD8 gene was found in roots under Pi deficiency (Figure 1). Because SL levels are elevated under Pi deficiency in tomato [15], we measured the SL levels in root exudates and roots of WT and $\operatorname{slccd} 8$ mutants grown under Pi deficiency. In the slccd8 mutants, the tomato endogenous SLs orobanchol and solanacol were undetectable (Figure 2A-D), and root exudates of the slccd 8 mutants barely induced germination of the root-parasitic plants $O$. minor and P. aegyptiaca (Figure 2E,F). These results indicate that SLs are barely produced in the mutants.

A
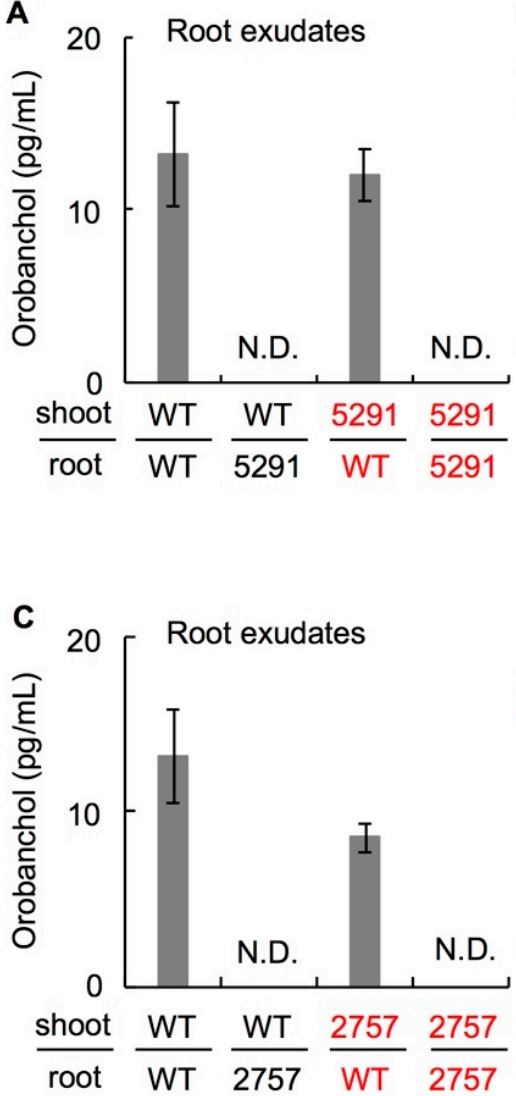
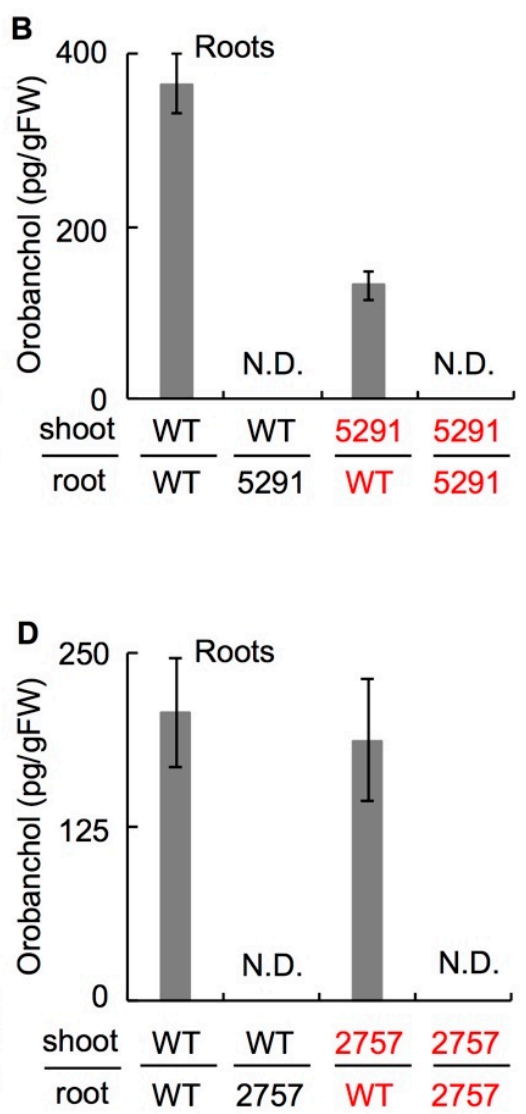

Figure 6. Orobanchol levels in root exudates and roots in different grafting combinations, between WT and slccd8 mutants. (A) $n=4-9$. (B) $n=4-6$. (C) $n=11-18$. (D) $n=6-8$. Error bars, S.E.; N.D., not detected.

The number of branches was higher in the slccd8 mutants than in WT (Figure 3) and was reduced by GR24 treatment (Figure 4, Figure S3). In the slccd8, axillary bud formation was not stimulated, but growth of dormant buds was activated in comparison with WT. However, this difference was smaller than that of between the knock-down lines of SL-biosynthetic genes and their parent cultivars $[25,26]$ because plant size of Micro-Tom is small and the total number of axillary buds is low. In addition, there is no significant effect on GR24 treatment in WT of Micro-Tom because of the small size and small number of axillary buds. SlCCD8 expression was very low in flowers and fruits (Figure 1B); 
no significant differences were detected in several fruit traits that we checked (Figure S7). When slccd8 mutant shoot scions were grafted onto WT rootstocks, the number of branches in the slccd8 mutants decreased and became similar to that of WT (Figure 5, Figure S4). This result indicates that SLs produced in roots were transported to the scions and is consistent with grafting experiments in the rms1 mutant of pea and the max4 mutant of Arabidopsis, which are CCD8-defective mutants [39,40]. SL transportation from roots to shoots is regulated by PDR1, which encodes an ATP-binding cassette transporter [41]. Because only small amounts of SLs were produced in WT shoot scions, SLs were hardly transported to $s l c c d 8$ mutant rootstocks (Figure 6, Figure S5).

Phelipanche aegyptiaca, a holoparasitic plant that infects important dicotyledonous crops, including tomato [42], is the main limiting factor in processing-tomato production in Israel and some countries of the Arabian Peninsula [43]. The annual economic losses caused by P. aegyptiaca infection increase continuously; infection is not completely suppressed by available herbicides [43]. A tomato mutant with decreased SL production, Sl-ORT1, induced by fast-neutron irradiation, is resistant to Orobanche and Phelipanche spp. [44,45]. In Sl-ORT1, the transcription level of CCD7 is lower than that in WT [46], but the mutation and the mechanism of SL deficiency are unknown. The rice CCD8-defective mutant $d 10$ is infected by fewer S. hermonthica plants than WT [4]. Infection of SlCCD8 RNAi lines by P. ramosa is $10 \%$ of that in WT seedlings [25]. Probably, small amounts of SLs were produced in roots of the RNAi lines and causes the infection of P. ramosa. However, these lines are more prone to infection by pre-germinated P. ramosa and the parasite develops faster than in WT, suggesting a positive role of SLs in host defense against parasitic plant infection [47]. The reduced levels of defense-related hormones such as jasmonic, salicylic, and abscisic acids in the SICCD8 RNAi lines [48] may contribute to their increased susceptibility to parasite infection.

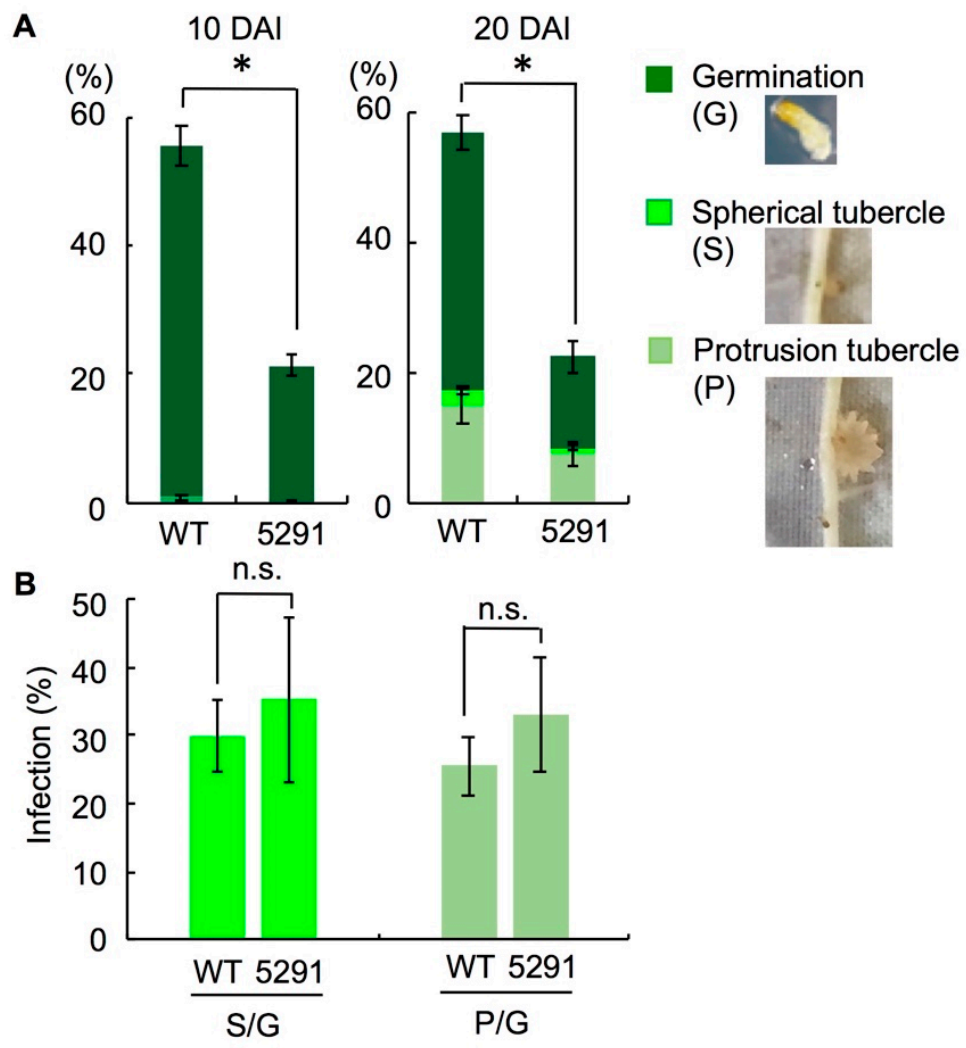

Figure 7. Infection assay with Phelipanche aegyptiaca. (A) Proportion of germinated P. aegyptiaca seeds, spherical tubercles, and protrusion tubercles 10 and 20 days after inoculation (DAI) of tomato roots $(n=3)$. (B) Infection with germinated P. aegyptiaca seeds $20 \mathrm{DAI}(n=3)$. S/G and P/G mean frequency of spherical tubercles and protrusion tubercles to germinated Phelipanche, respectively. Error bars, S.E.; ${ }^{*} p<0.05$ (Student's $t$-test); n.s., not significant. 
In this study, P. aegyptiaca infection of the roots was lower in the slccd8 mutants than in WT because of a significantly lower germination of P. aegyptiaca around the roots of the mutants (Figure 7A). In germination assay, root exudates of the $\operatorname{slcc} 8$ mutants which were extracted with ethyl acetate barely stimulated germination of P. aegyptiaca ( 1\%; Figure $2 \mathrm{~F})$, whereas germination of P. aegyptiaca was approximately $23 \%$ in infection assay (Figure 7A). SLs are major germination stimulants for the roots of parasitic plants, but some Orobanche and Phelipanche spp. use other germination signals. Orobanche cumana, a parasite which infects sunflowers, recognizes dehydrocostus lactone [49]. Phelipanche ramosa responds to glucosinolate-breakdown products derived from rapeseed oil [50]. These data indicate that not only SLs, but also compounds other than SLs might be produced in Micro-Tom roots and stimulate germination of P. aegyptiaca. The slccd8 mutants failed to prevent infection once P. aegyptiaca had germinated (Figure 7B). To completely block P. aegyptiaca infection in tomato, aqueous compounds inducing germination should be identified and their biosynthesis should be suppressed.

\section{Materials and Methods}

\subsection{Plant Material and Growth Conditions}

Seeds of the wild type and the slccd8 mutant $\mathrm{M}_{3}$ line of Micro-Tom (Solanum lycopersicum $\mathrm{L}$.) were provided by the University of Tsukuba. The seeds were surface-sterilized in $1 \%$ sodium hypochlorite solution containing $0.05 \%$ Tween 20 for $2 \mathrm{~min}$ and rinsed with sterile water five times. The sterile seeds were placed on half-strength Murashige and Skoog (MS) medium [51] containing $0.6 \%$ agar in PLANTAN culture pots (Sibata, Saitama, Japan), and cultured in a plant incubator FLI-2000 (Eyela, Tokyo, Japan) with a 16-h light/8-h dark photoperiod $\left(63 \mu \mathrm{mol} \mathrm{m}{ }^{-2} \cdot \mathrm{s}^{-1}\right)$ at $23{ }^{\circ} \mathrm{C}$ for 10 days. The plants were then transferred to half-strength Hoagland's culture medium [52] with (+Pi) or without $\mathrm{Pi}(-\mathrm{Pi})$. In the grafting experiment, 10-day-old seedlings were divided into shoot scions and rootstocks. Combination of the grafting was WT scions onto WT root stocks, WT scions onto root stocks of $s l c c d 8$ mutant, slccd8 mutant scions onto WT root stocks, and slccd8 mutant scions onto root stocks of slccd 8 mutant. The graft junction was fixed with a silicone tube. Branches $>2 \mathrm{~mm}$ long were counted 50 days after grafting. For evaluation of flower and fruit traits, seedlings were grown in mixed soil (vermiculite:Metro-Mix = 1:1). Brix and acidity were measured using a PAL-BX/ACID3 master kit (Atago, Tokyo, Japan).

\subsection{Screening for slccd8 Mutants}

slccd 8 mutants were screened by the TILLING method as described [53] from about 9000 mutagenized $\mathrm{M}_{2}$ lines [54]. Genomic DNA was extracted from $\mathrm{M}_{3}$ leaves (ca. $20 \mathrm{mg}$ ) of Micro-Tom in $400 \mu \mathrm{L}$ of DNA extraction buffer (200 mM Tris.HCL, $250 \mathrm{mM} \mathrm{NaCl}, 25 \mathrm{mM}$ EDTA, and 0.5\% SDS, pH 7.5) using a BioMasher II homogenizer (Nippi, Inc., Tokyo, Japan). The extract was centrifuged at $8000 \times g$ for $1 \mathrm{~min}$, the supernatant $(300 \mu \mathrm{L})$ was transferred to a new 1.5-mL tube, and 2-propanol $(300 \mu \mathrm{L})$ was added and gently mixed for $2 \mathrm{~min}$. The mixture was centrifuged at 11,000 rpm for $5 \mathrm{~min}$, the supernatant was removed, and the pellet was dissolved in $100 \mu \mathrm{L}$ of TE. from $\mathrm{M}_{2}$ leaves, and PCR was performed using $5^{\prime}$ end-IRDye-labeled $s l c c d 8$-specific primers to amplify the desired region. PCR primers for TILLING were designed in Genetyx v. 10 software (Genetyx corporation, Tokyo, Japan) and are shown in Supplementary Table S2. PCR conditions were as follows: Initial denaturation at $95^{\circ} \mathrm{C}$ for $2 \mathrm{~min}$; 40 cycles of $95^{\circ} \mathrm{C}$ for $30 \mathrm{~s}, 60^{\circ} \mathrm{C}$ for $30 \mathrm{~s}$, and $72{ }^{\circ} \mathrm{C}$ for $1 \mathrm{~min}$; and a final extension at $72{ }^{\circ} \mathrm{C}$ for $5 \mathrm{~min}$. Heteroduplexes of the PCR products were formed by heating at $95^{\circ} \mathrm{C}$ for $7 \mathrm{~min}$ and gradual cooling to $4{ }^{\circ} \mathrm{C}$. Recombinant SIENDO1 nuclease was used to cleave the base mismatches at $45^{\circ} \mathrm{C}$ for $20 \mathrm{~min}$ [55]. Digested fragments were purified using Sephadex-G50 gel and concentrated at $85^{\circ} \mathrm{C}$ for $80 \mathrm{~min}$. TILLING screening was performed using a LI-COR DNA analyzer (LI-COR Biotechnology, Lincoln, NE, USA) as described [56]. 


\subsection{CAPS Method}

Genomic DNA was extracted from young leaves (ca. $20 \mathrm{mg}$ ) of Micro-Tom as above. PCR was carried out with 5291- and 2757-specific primers (Supplementary Table S2). For screening of recessive homozygous mutants, the amplified PCR products were digested with Hpy188I and MboII, respectively. The difference in restriction fragment patterns between WT and mutants was confirmed by $2 \%$ agarose electrophoresis.

\subsection{Analysis SlCCD8 Gene Expression}

Total RNA was extracted from stems, roots, leaves, shoot apexes, flower buds, flowers, and fruits, using an RNeasy Plant Mini Kit (Qiagen, Hilden, Germany). RNA concentration was measured using a NanoDrop 200c spectrophotometer (Agilent Technologies, Santa Clara, CA, USA). An aliquot (200 ng) was used for cDNA synthesis with a ReverTra Ace qPCR RT Kit (Toyobo, Osaka, Japan). qRT-PCR was performed using a Thunderbird Probe qPCR Mix (Toyobo), specific primers, and probes listed in Supplementary Table S2. Expression of SL-related genes was analyzed by a real time PCR system StepOnePlus (Thermo Fisher Scientific, Waltham, MA, USA). The SIEF1- $\alpha$ gene was used as an internal standard $[57,58]$.

\subsection{Chemicals}

rac-GR24 was purchased from Chiralix (Nijmegen, The Netherlands). Orobanchol and solanacol were synthesized as described [59,60]. [6 $\left.6^{\prime}-D_{1}\right]$-Orobanchol was described in [61]. [ $\left.6^{\prime}-{ }^{13} C_{1}\right]$-solanacol $\left(( \pm)\right.$-(3aR* $\left.{ }^{*}, 4 R^{*}, 8 b R^{*}\right)-4$-Hydroxy-7,8-dimethyl-3,3a,4,8b-tetrahydro-2H-indeno[1,2-b]furan-2-one) was synthesized as reported (Figure S8) [59]. Ester condensation of the racemic 4-hydroxy ABC lactone with methyl $\left[1-{ }^{13} \mathrm{C}\right]$ formate by the use of sodium hydride in $\mathrm{N}, \mathrm{N}$-dimethylformamide followed by alkylation with racemic 4-bromo-2-methyl-2-buten-4-olide provided $( \pm)-\left[6^{\prime}-{ }^{13} C_{1}\right]$-solanacol and $( \pm)-\left[6^{\prime}-{ }^{13} C_{1}\right]-2^{\prime}$-epi-solanacol. $( \pm)-\left[6^{\prime}-{ }^{13} C_{1}\right]$-Solanacol was purified by a silica gel column (Kieselgel 60, Merck, n-hexane-ethyl acetate stepwise) and semi-preparative HPLC (Inertsil SIL-100A, GL Sciences, $20 \%$ ethanol in n-hexane). NMR spectra were obtained with a JEOL JNM-ECZ500R NMR spectrometer. Chemical shifts were referenced to tetramethylsilane as an internal standard. Mass spectra were recorded on an Waters Xevo QTof MS mass spectrometer. $( \pm)-\left[6^{\prime}{ }^{13} \mathrm{C}_{1}\right]$-Solanacol: ${ }^{1} \mathrm{H}-\mathrm{NMR}\left(\mathrm{CDCl}_{3}\right.$,

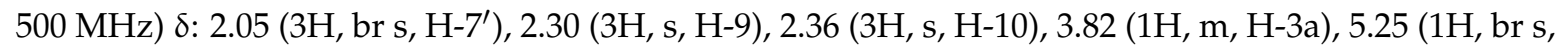
H-4), $6.16(1 \mathrm{H}, \mathrm{d}, \mathrm{J}=7.5 \mathrm{~Hz}, \mathrm{H}-8 \mathrm{~b}), 6.23\left(1 \mathrm{H}, \mathrm{m}, \mathrm{H}-2^{\prime}\right), 7.00\left(1 \mathrm{H}, \mathrm{m}, \mathrm{H}-3^{\prime}\right), 7.17(1 \mathrm{H}, \mathrm{d}, \mathrm{J}=7.7 \mathrm{~Hz}, \mathrm{H}-6)$, $7.24(1 \mathrm{H}, \mathrm{d}, \mathrm{J}=7.7 \mathrm{~Hz}, \mathrm{H}-5), 7.56\left(1 \mathrm{H}, \mathrm{dd},{ }^{1} \mathrm{~J}_{\mathrm{CH}}=186.2 \mathrm{~Hz},{ }^{4} \mathrm{~J}_{\mathrm{HH}}=2.3 \mathrm{~Hz}, \mathrm{H}-6{ }^{\prime}\right) ;$ HR-ESI-TOF-MS $m / z$ : $344.1234[\mathrm{M}+\mathrm{H}]^{+}$(calcd. for $\mathrm{C}_{18}{ }^{13} \mathrm{CH}_{19} \mathrm{O}_{6}, m / z: 344.1215$ ).

\subsection{Quantitative Analysis of SLs by LC-MS/MS}

Hydroponic culture medium $(10 \mathrm{~mL})$ was collected, $\left[6^{\prime}-\mathrm{D}_{1}\right]$-orobanchol and $\left[6^{\prime}-{ }^{13} \mathrm{C}\right]$-solanacol (200 pg each) were added as internal standards and the medium was extracted with $4 \mathrm{~mL}$ of ethyl acetate twice. The ethyl acetate phase was evaporated to dryness under nitrogen and dissolved in ethyl acetate: n-hexane (35:65). The extracts were loaded onto Sep-Pak Silica 1-mL cartridges (Waters, Milford, MA, USA) and washed with ethyl acetate: n-hexane (35:65), and SLs were then eluted with ethyl acetate: n-hexane (50:50). To measure endogenous SL levels in roots, the roots $(0.1-0.5 \mathrm{~g})$ were homogenized in $5 \mathrm{~mL}$ of acetone containing $\left[6^{\prime}-\mathrm{D}_{1}\right]$-orobanchol and $\left[6^{\prime}-{ }^{13} \mathrm{C}\right]$-solanacol (200 pg each) and filtered to remove the residues. The filtrates were evaporated to dryness under nitrogen, dissolved in $4 \mathrm{~mL}$ of Milli-Q water, added $20 \mu \mathrm{L}$ of $1 \mathrm{~N} \mathrm{HCl}$, and extracted with $4 \mathrm{~mL}$ of ethyl acetate twice. The ethyl acetate phase was evaporated to dryness under nitrogen. The extracts were dissolved in 10\% acetone and loaded onto Oasis HLB 3-mL cartridges (Waters) and eluted with $3 \mathrm{~mL}$ of $60 \%$ acetone twice. The eluates were evaporated to dryness under nitrogen, dissolved in ethyl acetate: n-hexane (35:65), and chromatographed on Sep-Pak Silica 1-mL cartridges as above. SL fractions were dissolved in 50\% acetonitrile and analyzed by LC-MS/MS on a quadrupole tandem 
mass spectrometer (3200 QTRAP; Sciex, Framingham, MA, USA) and a high-performance liquid chromatograph (Prominence; Shimadzu, Kyoto, Japan) equipped with a reverse-phase column (Acquity UPLC BEH-C18, $\varnothing 2.1 \mathrm{~mm} \times 50 \mathrm{~mm}, 1.7 \mu \mathrm{m}$; Waters). Qualitative analysis of the data was performed in Analyst v. 1.5.1 software, and fragment analysis was performed in MultiQuant v. 2.0.2 software (both from Sciex).

\subsection{Germination of Root-Parasitic Plant Seeds}

Germination assays with O. minor and P. aegyptiaca seeds were performed as described [16]. Culture medium $(10 \mathrm{~mL})$ was collected after 2 weeks of hydroponic culture without Pi and extracted with $4 \mathrm{~mL}$ of ethyl acetate twice. The ethyl acetate layer was evaporated to dryness under nitrogen. The samples were then dissolved in $600 \mu \mathrm{L}$ of Milli-Q water. Seeds of parasites were surface sterilized in $1 \%$ sodium hypochlorite containing $0.05 \%$ Tween 20 for $2 \mathrm{~min}$ and conditioned at $23^{\circ} \mathrm{C}$ for 7 days on moist glass fiber filters (GF/A, Whatman, Maidstone, UK). The filters were moved to each well of a 96-well plate after conditioning, $20 \mu \mathrm{L}$ of $1 \times 10^{-5}-1 \times 10^{-9} \mathrm{M}$ GR24 solution, Milli-Q water, or the sample solution was added to each well, and the seeds were incubated at $23{ }^{\circ} \mathrm{C}$ for 7 days. Germinated seeds were counted microscopically.

\subsection{Measurement of Membrane Ion Leakage and Chlorophyll Contents}

Micro-Tom leaf disks were collected 24 days after sowing and floated on $2.5 \mathrm{mM}$ MES buffer ( $\mathrm{pH}$ 5.7) containing $0.05 \%$ Tween 20 for 0-16 days. After incubation, the buffer was diluted to one-third of its initial concentration with Milli-Q water, and electrical conductivity was measured using an ES-51 electrical conductivity meter (Horiba, Kyoto, Japan). The leaf segments were placed in 1.5-mL tubes containing zirconia beads, frozen in liquid nitrogen, and crushed in a vortex mixer. Chlorophylls were extracted from each leaf segment in $80 \%$ acetone. Absorbance at 663.2 and $646.8 \mathrm{~nm}$ was measured in a DU720 spectrometer (Beckman Coulter, La Brea, CA, USA). Chlorophyll contents were calculated as described [62].

\subsection{Root Infection with Phelipanche aegyptiaca}

Infection assay with P. aegyptiaca was performed according to [63]. The seeds were surface sterilized, allowed to imbibe on filter paper for 7 days at $25^{\circ} \mathrm{C}$, and then cultured on MS medium containing 3\% sucrose and $0.8 \%$ agar for 4 days. WT and line 5291 seeds were allowed to imbibe on filter paper for 5 days and were then cultured Hoagland's culture medium for 4 weeks. Twenty P. aegyptiaca seeds were placed around one host root. Germination rate was evaluated by using 200 seeds each with three replicates. We calculated the proportion of germination and the formation of spherical and protrusion-like tubercles at 10 and 20 DAI.

Supplementary Materials: Supplementary materials can be found at http:/ /www.mdpi.com/1422-0067/19/9/ $2645 /$ s1.

Author Contributions: S.H., T.T., S.F. performed the experiments on phenotype, grafting, qRT-PCR, Orogbanche germination assay, and SL analysis. Y.O., T.A., H.E. performed TILLING for slccd8 mutant screening. J.S. and K.A. (Koh Aoki) performed germination and infection assay of P. aegyptiaca. M.K., K.Y., and K.A. (Kohki Akiyama) prepared SL internal standard. M.S. established method for SL analysis. Y.Y. prepared plasmid for qRT-PCR. K.S., S.Y., and M.U. designed the experiments. S.H., K.A. (Koh Aoki), K.A. (Kohki Akiyama) and M.U. wrote the paper.

Funding: This work was in part supported by grants from Toyo University (the Inoue Enryo Memorial Foundation for Promoting Sciences to S.H.), and from the Japan Society for the Promotion of Science (KAKENHI Grant Nos. 17K07650 to M.U., 16K18560 to K.Y., and 16H04875 to K.A.), the Japan Science and Technology Agency PRESTO, and by a Cooperative Research Grant of the Plant Transgenic Design Initiative (PTradD) by the Gene Research Center, Tsukuba Plant Innovation Research Center, University of Tsukuba (to S.Y. and M.U.).

Acknowledgments: We thank Yu Kasuo, Jiei Tanikawa, Atsuya Kubota, Karen Endo, and Nao Tsunoda (Toyo University) for their technical assistance, Koichi Yoneyama (Utsunomiya University) for providing O. minor seeds, Joseph Hershenhorn and Dina Plakhine (Newe-Ya'ar Research Center, Agriculture Research Organization, Israel) for providing P. aegyptiaca seeds, and Shosaku Kashiwada, Hiroki Higashibata, Yuichi Iwasaki, and Uma Maheswari Rajagopalan (Toyo University) for constructive comments. Tomato seeds (TOMJPF00001, TOMJPE7343, 
$7024,8245,7311,5639,7720,8940,2481,5550,3979,5291$, and 2757) were provided by the University of Tsukuba, Gene Research Center, through National Bio-Resource Project of the Japan Agency for Medical Research and Development. This work was in part supported by the Research Center for Life and Environmental Sciences, Toyo University.

Conflicts of Interest: The authors declare no conflict of interest.

\section{Abbreviations}

$\begin{array}{ll}\text { 4DO } & \text { 4-deoxyorobanchol } \\ \text { CAPS } & \begin{array}{l}\text { cleaved amplified polymorphic sequence } \\ \text { carotenoid cleavage dioxygenase }\end{array} \\ \text { CCD } & \text { carlactone } \\ \text { CL } & \text { day after innoculation } \\ \text { DAI } & \text { liquid chromatography-tandem mass spectrometry } \\ \text { LC-MS/MS } & \text { Murashige and Skoog } \\ \text { MS } & \text { not detected } \\ \text { N.D. } & \text { no germination } \\ \text { N.G. } & \text { not significant } \\ \text { n.s. } & \text { inorganic phosphate } \\ \text { Pi } & \text { standard error } \\ \text { S.E. } & \text { strigolactone } \\ \text { SL } & \text { targeting-induced local lesions in genome } \\ \text { TILLING } & \text { wild-type } \\ \text { WT } & \end{array}$

\section{References}

1. Steeves, T.A.; Sussex, I.M. Patterns in Plant Development, 2nd ed.; Cambridge University Press: Cambridge, UK, 1989.

2. McSteen, P.; Leyser, O. Shoot branching. Annu. Rev. Plant Biol. 2005, 56, 353-374. [CrossRef] [PubMed]

3. Ongaro, V.; Leyser, O. Hormonal control of shoot branching. J. Exp. Bot. 2008, 59, 67-74. [CrossRef] [PubMed]

4. Umehara, M.; Hanada, A.; Yoshida, S.; Akiyama, K.; Arite, T.; Takeda-Kamiya, N.; Magome, H.; Kamiya, Y.; Shirasu, K.; Yoneyama, K.; et al. Inhibition of shoot branching by new terpenoid plant hormones. Nature 2008, 455, 195-200. [CrossRef] [PubMed]

5. Gomez-Roldan, V.; Fermas, S.; Brewer, P.B.; Puech-Pages, V.; Dun, E.A.; Pillot, J.P.; Letisse, F.; Matusova, R.; Danoun, S.; Portais, J.C.; et al. Strigolactone inhibition of shoot branching. Nature 2008, 455, 189-194. [CrossRef] [PubMed]

6. Xie, X.N.; Yoneyama, K.; Yoneyama, K. The strigolactone story. Annu. Rev. Phytopathol. 2010, 48, 93-117. [CrossRef] [PubMed]

7. Alder, A.; Jamil, M.; Marzorati, M.; Bruno, M.; Vermathen, M.; Bigler, P.; Ghisla, S.; Bouwmeester, H.; Beyer, P.; Al-Babili, S. The path from $\beta$-carotene to carlactone, a strigolactone-like plant hormone. Science 2012, 335, 1348-1351. [CrossRef] [PubMed]

8. Seto, Y.; Sado, A.; Asami, K.; Hanada, A.; Umehara, M.; Akiyama, K.; Yamaguchi, S. Carlactone is an endogenous biosynthetic precursor for strigolactones. Proc. Natl. Acad. Sci. USA 2014, 111, 1640-1645. [CrossRef] [PubMed]

9. Arite, T.; Iwata, H.; Ohshima, K.; Maekawa, M.; Nakajima, M.; Kojima, M.; Sakakibara, H.; Kyozuka, J. Dwarf10, an rms1/max4/dad1 ortholog, controls lateral bud outgrowth in rice. Plant J. 2007, 51, 1019-1029. [CrossRef] [PubMed]

10. Foo, E.; Bullier, E.; Goussot, M.; Foucher, F.; Rameau, C.; Beveridge, C.A. The branching gene RAMOSUS1 mediates interactions among two novel signals and auxin in pea. Plant Cell 2005, 17, 464-474. [CrossRef] [PubMed]

11. Abe, S.; Sado, A.; Tanaka, K.; Kisugi, T.; Asami, K.; Ota, S.; Kim, H.I.; Yoneyama, K.; Xie, X.; Ohnishi, T.; et al. Carlactone is converted to carlactonoic acid by max 1 in arabidopsis and its methyl ester can directly interact with atd14 in vitro. Proc. Natl. Acad. Sci. USA 2014, 111, 18084-18089. [CrossRef] [PubMed] 
12. Zhang, Y.; van Dijk, A.D.; Scaffidi, A.; Flematti, G.R.; Hofmann, M.; Charnikhova, T.; Verstappen, F.; Hepworth, J.; van der Krol, S.; Leyser, O.; et al. Rice cytochrome p450 max1 homologs catalyze distinct steps in strigolactone biosynthesis. Nat. Chem. Biol. 2014, 10, 1028-1033. [CrossRef] [PubMed]

13. Yoneyama, K.; Xie, X.; Kusumoto, D.; Sekimoto, H.; Sugimoto, Y.; Takeuchi, Y.; Yoneyama, K. Nitrogen deficiency as well as phosphorus deficiency in sorghum promotes the production and exudation of 5-deoxystrigol, the host recognition signal for arbuscular mycorrhizal fungi and root parasites. Planta 2007, 227, 125-132. [CrossRef] [PubMed]

14. Yoneyama, K.; Yoneyama, K.; Takeuchi, Y.; Sekimoto, H. Phosphorus deficiency in red clover promotes exudation of orobanchol, the signal for mycorrhizal symbionts and germination stimulant for root parasites. Planta 2007, 225, 1031-1038. [CrossRef] [PubMed]

15. Lopez-Raez, J.A.; Charnikhova, T.; Gomez-Roldan, V.; Matusova, R.; Kohlen, W.; De Vos, R.; Verstappen, F.; Puech-Pages, V.; Becard, G.; Mulder, P.; et al. Tomato strigolactones are derived from carotenoids and their biosynthesis is promoted by phosphate starvation. New Phytol. 2008, 178, 863-874. [CrossRef] [PubMed]

16. Sugimoto, Y.; Ueyama, T. Production of (+)-5-deoxystrigol by Lotus japonicus root culture. Phytochemistry 2008, 69, 212-217. [CrossRef] [PubMed]

17. Umehara, M.; Hanada, A.; Magome, H.; Takeda-Kamiya, N.; Yamaguchi, S. Contribution of strigolactones to the inhibition of tiller bud outgrowth under phosphate deficiency in rice. Plant Cell Physiol. 2010, 51, 1118-1126. [CrossRef] [PubMed]

18. Akiyama, K.; Matsuzaki, K.; Hayashi, H. Plant sesquiterpenes induce hyphal branching in arbuscular mycorrhizal fungi. Nature 2005, 435, 824-827. [CrossRef] [PubMed]

19. Kohlen, W.; Charnikhova, T.; Liu, Q.; Bours, R.; Domagalska, M.A.; Beguerie, S.; Verstappen, F.; Leyser, O.; Bouwmeester, H.; Ruyter-Spira, C. Strigolactones are transported through the xylem and play a key role in shoot architectural response to phosphate deficiency in nonarbuscular mycorrhizal host arabidopsis. Plant Physiol. 2010, 155, 974-987. [CrossRef] [PubMed]

20. Umehara, M. Strigolactone, a key regulator of nutrient allocation in plants. Plant Biotechnol. 2011, 28, 429-437. [CrossRef]

21. Sun, H.; Tao, J.; Liu, S.; Huang, S.; Chen, S.; Xie, X.; Yoneyama, K.; Zhang, Y.; Xu, G. Strigolactones are involved in phosphate- and nitrate-deficiency-induced root development and auxin transport in rice. J. Exp. Bot. 2014, 65, 6735-6746. [CrossRef] [PubMed]

22. Shindo, M.; Shimomura, K.; Yamaguchi, S.; Umehara, M. Upregulation of dwarf27 is associated with increased strigolactone levels under sulfur deficiency in rice. Plant Direct 2018, 2, e00050. [CrossRef]

23. Consortium, T.G. The tomato genome sequence provides insights into fleshy fruit evolution. Nature 2012, 485, 635-641. [CrossRef] [PubMed]

24. Kohlen, W.; Charnikhova, T.; Bours, R.; Lopez-Raez, J.A.; Bouwmeester, H. Tomato strigolactones: A more detailed look. Plant Signal. Behav. 2013, 8, e22785. [CrossRef] [PubMed]

25. Kohlen, W.; Charnikhova, T.; Lammers, M.; Pollina, T.; Toth, P.; Haider, I.; Pozo, M.J.; de Maagd, R.A.; Ruyter-Spira, C.; Bouwmeester, H.J.; et al. The tomato carotenoid cleavage dioxygenase8 (slccd8) regulates rhizosphere signaling, plant architecture and affects reproductive development through strigolactone biosynthesis. New Phytol. 2012, 196, 535-547. [CrossRef] [PubMed]

26. Vogel, J.T.; Walter, M.H.; Giavalisco, P.; Lytovchenko, A.; Kohlen, W.; Charnikhova, T.; Simkin, A.J.; Goulet, C.; Strack, D.; Bouwmeester, H.J.; et al. Slccd7 controls strigolactone biosynthesis, shoot branching and mycorrhiza-induced apocarotenoid formation in tomato. Plant J. 2010, 61, 300-311. [CrossRef] [PubMed]

27. Zhang, Y.; Cheng, X.; Wang, Y.; Diez-Simon, C.; Flokova, K.; Bimbo, A.; Bouwmeester, H.J.; Ruyter-Spira, C. The tomato max1 homolog, slmax1, is involved in the biosynthesis of tomato strigolactones from carlactone. New Phytol. 2018, 219, 297-309. [CrossRef] [PubMed]

28. Cook, C.E.; Whichard, L.P.; Turner, B.; Wall, M.E.; Egley, G.H. Germination of witchweed (striga lutea lour.): Isolation and properties of a potent stimulant. Science 1966, 154, 1189-1190. [CrossRef] [PubMed]

29. Cook, C.E.; Whichard, L.P.; Wall, M.E.; Egley, G.H.; Coggon, P.; Luhan, P.A.; McPhail, A.T. Germination stimulants. 2. The structure of strigol-a potent seed germination stmulant for witchweed (striga lutea lour.). J. Am. Chem. Soc. 1972, 94, 6198-6199. [CrossRef]

30. Bouwmeester, H.J.; Matusova, R.; Zhongkui, S.; Beale, M.H. Secondary metabolite signalling in host-parasitic plant interactions. Curr. Opin. Plant Biol. 2003, 6, 358-364. [CrossRef] 
31. Bouwmeester, H.J.; Roux, C.; Lopez-Raez, J.A.; Becard, G. Rhizosphere communication of plants, parasitic plants and am fungi. Trends Plant Sci. 2007, 12, 224-230. [CrossRef] [PubMed]

32. Parker, C. Observations on the current status of orobanche and striga problems worldwide. Pest Manag. Sci. 2009, 65, 453-459. [CrossRef] [PubMed]

33. Mangnus, E.M.; Dommerholt, F.J.; Dejong, R.L.P.; Zwanenburg, B. Improved synthesis of strigol analog gr24 and evaluation of the biological-activity of its diastereomers. J. Agric. Food Chem. 1992, 40, 1230-1235. [CrossRef]

34. Yamada, Y.; Furusawa, S.; Nagasaka, S.; Shimomura, K.; Yamaguchi, S.; Umehara, M. Strigolactone signaling regulates rice leaf senescence in response to a phosphate deficiency. Planta 2014, 240, 399-408. [CrossRef] [PubMed]

35. Ueda, H.; Kusaba, M. Strigolactone regulates leaf senescence in concert with ethylene in arabidopsis. Plant Physiol. 2015, 169, 138-147. [CrossRef] [PubMed]

36. Gao, J.; Zhang, T.; Xu, B.; Jia, L.; Xiao, B.; Liu, H.; Liu, L.; Yan, H.; Xia, Q. Crispr/cas9-mediated mutagenesis of carotenoid cleavage dioxygenase 8 (ccd8) in tobacco affects shoot and root architecture. Int. J. Mol. Sci. 2018, 19, 1062. [CrossRef] [PubMed]

37. Pasare, S.A.; Ducreux, L.J.; Morris, W.L.; Campbell, R.; Sharma, S.K.; Roumeliotis, E.; Kohlen, W.; van der Krol, S.; Bramley, P.M.; Roberts, A.G.; et al. The role of the potato (Solanum tuberosum) ccd8 gene in stolon and tuber development. New Phytol. 2013, 198, 1108-1120. [CrossRef] [PubMed]

38. Liang, J.L.; Zhao, L.J.; Challis, R.; Leyser, O. Strigolactone regulation of shoot branching in chrysanthemum (dendranthema grandiflorum). J. Exp. Bot. 2010, 61, 3069-3078. [CrossRef] [PubMed]

39. Beveridge, C.A.; Symons, G.M.; Murfet, I.C.; Ross, J.J.; Rameau, C. The rms1 mutant of pea has elevated indole-3-acetic acid levels and reduced root-sap zeatin riboside content but increased branching controlled by graft-transmissible signal(s). Plant Physiol. 1997, 115, 1251-1258. [CrossRef]

40. Bainbridge, K.; Sorefan, K.; Ward, S.; Leyser, O. Hormonally controlled expression of the arabidopsis max4 shoot branching regulatory gene. Plant J. 2005, 44, 569-580. [CrossRef] [PubMed]

41. Kretzschmar, T.; Kohlen, W.; Sasse, J.; Borghi, L.; Schlegel, M.; Bachelier, J.B.; Reinhardt, D.; Bours, R.; Bouwmeester, H.J.; Martinoia, E. A petunia abc protein controls strigolactone-dependent symbiotic signalling and branching. Nature 2012, 483, 341-344. [CrossRef] [PubMed]

42. Joel, D.M.; Hershenhorn, J.; Eizenberg, H.; Aly, R.; Ejeta, G.; Rich, P.J.; Ransom, J.K.; Sauerborn, J.; Rubiales, D. Biology and management of weedy root parasites. Hortic. Rev. 2007, 33, 267-349.

43. Hershenhorn, J.; Eizenberg, H.; Dor, E.; Kapulnik, Y.; Goldwasser, Y. Phelipanche aegyptiaca management in tomato. Weed Res. 2009, 49, 34-47. [CrossRef]

44. Dor, E.; Alperin, B.; Wininger, S.; Ben-Dor, B.; Somvanshi, V.S.; Koltai, H.; Kapulnik, Y.; Hershenhorn, J. Characterization of a novel tomato mutant resistant to the weedy parasites orobanche and phelipanche spp. Euphytica 2010, 171, 371-380. [CrossRef]

45. Dor, E.; Yoneama, K.; Wininger, S.; Kapulnik, Y.; Koltai, H.; Xiaonan, X.; Hershenhorn, J. Strigolactone deficiency confers resistance in tomato line sl-ort1 to the parasitic weeds phelipanche spp. and orobanche spp. Phytopathology 2011, 101, 213-222. [CrossRef] [PubMed]

46. Koltai, H.; LekKala, S.P.; Bhattacharya, C.; Mayzlish-Gati, E.; Resnick, N.; Wininger, S.; Dor, E.; Yoneyama, K.; Hershenhorn, J.; Joel, D.M.; et al. A tomato strigolactone-impaired mutant displays aberrant shoot morphology and plant interactions. J. Exp. Bot. 2010, 61, 1739-1749. [CrossRef] [PubMed]

47. Cheng, X.; Flokova, K.; Bouwmeester, H.; Ruyter-Spira, C. The role of endogenous strigolactones and their interaction with aba during the infection process of the parasitic weed phelipanche ramosa in tomato plants. Front. Plant Sci. 2017, 8, 392. [CrossRef] [PubMed]

48. Torres-Vera, R.; Garcia, J.M.; Pozo, M.J.; Lopez-Raez, J.A. Do strigolactones contribute to plant defence? Mol. Plant Pathol. 2014, 15, 211-216. [CrossRef] [PubMed]

49. Joel, D.M.; Chaudhuri, S.K.; Plakhine, D.; Ziadna, H.; Steffens, J.C. Dehydrocostus lactone is exuded from sunflower roots and stimulates germination of the root parasite orobanche cumana. Phytochemistry 2011, 72, 624-634. [CrossRef] [PubMed]

50. Auger, B.; Pouvreau, J.-B.; Pouponneau, K.; Yoneyama, K.; Montiel, G.; Le Bizec, B.; Yoneyama, K.; Delavault, P.; Delourme, R.; Simier, P. Germination stimulants of phelipanche ramosa in the rhizosphere of brassica napus are derived from the glucosinolate pathway. Mol. Plant Microbe Interact. 2012, 25, 993-1004. [CrossRef] [PubMed] 
51. Murashige, T.; Skoog, F. A revised medium for rapid growth and bio assays with tobacco tissue cultures. Physiol. Plant. 1962, 15, 473-497. [CrossRef]

52. Hoagland, D.R.; Arnon, D.I. The water-culture method for growing plants without soil. Calif. Agric. Exp. Stn. 1950, 347, 32.

53. Okabe, Y.; Asamizu, E.; Saito, T.; Matsukura, C.; Ariizumi, T.; Bres, C.; Rothan, C.; Mizoguchi, T.; Ezura, H. Tomato tilling technology: Development of a reverse genetics tool for the efficient isolation of mutants from micro-tom mutant libraries. Plant Cell Physiol. 2011, 52, 1994-2005. [CrossRef] [PubMed]

54. Saito, T.; Ariizumi, T.; Okabe, Y.; Asamizu, E.; Hiwasa-Tanase, K.; Fukuda, N.; Mizoguchi, T.; Yamazaki, Y.; Aoki, K.; Ezura, H. Tomatoma: A novel tomato mutant database distributing micro-tom mutant collections. Plant Cell Physiol. 2011, 52, 283-296. [CrossRef] [PubMed]

55. Triques, K.; Sturbois, B.; Gallais, S.; Dalmais, M.; Chauvin, S.; Clepet, C.; Aubourg, S.; Rameau, C.; Caboche, M.; Bendahmane, A. Characterization of arabidopsis thaliana mismatch specific endonucleases: Application to mutation discovery by tilling in pea. Plant J. 2007, 51, 1116-1125. [CrossRef] [PubMed]

56. Till, B.J.; Zerr, T.; Comai, L.; Henikoff, S. A protocol for tilling and ecotilling in plants and animals. Nat. Protoc. 2006, 1, 2465-2477. [CrossRef] [PubMed]

57. Gutierrez, L.; Mauriat, M.; Guenin, S.; Pelloux, J.; Lefebvre, J.F.; Louvet, R.; Rusterucci, C.; Moritz, T.; Guerineau, F.; Bellini, C.; et al. The lack of a systematic validation of reference genes: A serious pitfall undervalued in reverse transcription-polymerase chain reaction (rt-pcr) analysis in plants. Plant Biotechnol. J. 2008, 6, 609-618. [CrossRef] [PubMed]

58. Gong, P.; Zhang, J.; Li, H.; Yang, C.; Zhang, C.; Zhang, X.; Khurram, Z.; Zhang, Y.; Wang, T.; Fei, Z.; et al. Transcriptional profiles of drought-responsive genes in modulating transcription signal transduction, and biochemical pathways in tomato. J. Exp. Bot. 2010, 61, 3563-3575. [CrossRef] [PubMed]

59. Kumagai, H.; Fujiwara, M.; Kuse, M.; Takikawa, H. A concise synthesis of optically active solanacol, the germination stimulant for seeds of root parasitic weeds. Biosci. Biotechnol. Biochem. 2015, 79, 1240-1245. [CrossRef] [PubMed]

60. Hirayama, K.; Mori, K. Synthesis of (+)-strigol and (+)-orobanchol, the germination stimulants, and their stereoisomers by employing lipase-catalyzed asymmetric acetylationas the kkey step. Eur. J. Org. Chem. 1999, 1999, 2211-2217. [CrossRef]

61. Yoneyama, K.; Xie, X.; Kim, H.I.; Kisugi, T.; Nomura, T.; Sekimoto, H.; Yokota, T.; Yoneyama, K. How do nitrogen and phosphorus deficiencies affect strigolactone production and exudation? Planta 2012, 235, 1197-1207. [CrossRef] [PubMed]

62. Lichtenthaler, H.K. Chlorophylls and carotenoids: Pigments of photosynthtic biomembranes. Methods Enzymol. 1987, 148, 350-382.

63. Ekawa, M.; Aoki, K. Phloem-conducting cells in haustoria of the root-parasitic plant phelipanche aegyptiaca retain nuclei and are not mature sieve elements. Plants 2017, 6, 60. [CrossRef] [PubMed]

(C) 2018 by the authors. Licensee MDPI, Basel, Switzerland. This article is an open access article distributed under the terms and conditions of the Creative Commons Attribution (CC BY) license (http://creativecommons.org/licenses/by/4.0/). 